\title{
O FIM DO ENCANTO DA MATEMÁTICA UNIVERSAL: A APRENDIZAGEM MATEMÁTICA A PARTIR DE UMA PERSPECTIVA PÓS- ESTRUTURALISTA
}

\section{Karin Ritter Jelinek*}

\begin{abstract}
Resumo: O presente artigo busca problematizar a crença no universalismo da Matemática. Partindo dos pressupostos evidenciados pelos estudos etnomatemáticos, que deram visibilidade para o fato de que diferentes povos realizam práticas matemáticas singulares - relacionadas às suas práticas socioculturais - este estudo adentra à perspectiva pós-estruturalista. Assim, tal temática passa a ser analisada a partir de uma perspectiva que se afasta dos estruturalismos próprios do campo do conhecimento matemático, permitindo que se trabalhe com problematizações em que o processo de significação é incerto. Para empreender tal estudo, as discussões foram embasadas em autores como Walkerdine, Lave, Gottschalk, Miguel, Vilela e, fundamentalmente, em Wittgenstein. Como considerações finais - contudo provisórias - aponta-se como a aprendizagem matemática se relaciona com as práticas sociais, de forma que não faz mais sentido pensarmos em um caráter disciplinar para a Matemática na contemporaneidade.
\end{abstract}

Palavras-chave: práticas matemáticas; práticas sociais; caráter disciplinar; jogos de linguagem.

Resumen: El presente artículo busca problematizar la creencia en el universalismo de la Matemática. Partiendo de los presupuestos evidenciados por los estudios etnomatemáticos, que dieron visibilidad al hecho de que diferentes pueblos realizan prácticas matemáticas singulares - relacionadas a sus prácticas socioculturales - este estudio se adentra en la perspectiva post estructuralista. Así, tal temática pasa a ser analizada a partir de una perspectiva que se aleja de los estructuralismos propios del campo del conocimiento matemático, permitiendo que se trabaje con problematizaciones en las que el proceso de significación es incierto. Para emprender tal estudio, las discusiones se basaron en autores como Walkerdine, Lave, Gottschalk, Miguel, Vilela y, fundamentalmente, en Wittgenstein. Como consideraciones finales - sin embargo, provisorias - se señala cómo el aprendizaje matemático se relaciona con las prácticas sociales, de forma que no tiene más sentido pensar en un carácter disciplinario para la Matemática en la contemporaneidad.

Palabras claves: prácticas matemáticas; prácticas sociales; carácter disciplinario; juegos de lenguaje.

\section{Aspectos introdutórios}

$\mathrm{O}$ encanto se quebrou! $\mathrm{O}$ enfeitiçamento $^{2}$ do universalismo da Matemática já

\footnotetext{
* Doutora em Educação pela Universidade Federal do Rio Grande do Sul (UFRGS). Docente do Instituto de Matemática, Estatística e Física e do Programa de Pós-Graduação em Ensino de Ciências Exatas da Universidade Federal do Rio Grande (FURG). Integrante do grupo de pesquisa Praktiké - Educação e Currículo em Ciências e Matemática. Santo Antônio da Patrulha, RS, Brasil. E-mail: karinjelinek@furg.br.

2 A virada linguística, proposta pelo segundo Wittgenstein (2008, p.71), leva-nos à quebra dos enfeitiçamentos do nosso entendimento acerca da
}

não existe mais e há algum tempo já não podemos mais falar - nem acreditar! - na crença de que a Matemática é universal. Recentemente, através dos estudos da Etnomatemática, deu-se visibilidade para o fato de que diferentes povos realizam práticas matemáticas singulares, relacionadas às suas práticas socioculturais. Somam-se à isso os estudos que visam identificar as diferentes

existência dos padrões universais e das crenças na existência de uma pureza cultural.

JELINEK, Karin Ritter. O fim do encanto da matemática universal: A aprendizagem matemática a partir de uma perspectiva pós-estruturalista. Revista Sul-Americana de Filosofia e Educação. Número 32/33: nov. 2019 - out. 2020, p. 96-106. DOI: https://doi.org/10.26512/resafe.v1i32/33.35114 
concepções matemáticas, as ditas matemática científica, matemática da escola, matemática de rua, entre outras, e suas características que nos levam a diferenciá-las ${ }^{3}$.

Tais estudos levam-nos a acreditar que não existe uma matemática, universal, cristalizada, abstrata e desreferencializada. Dentre as diferentes matemáticas presentes na prática discursiva da Educação Matemática, duas ganham destaque: a matemática da escola e a matemática de rua, neste trabalho entendida como uma matemática não escolar.

É fato que as formas de fazer matemática na escola não se relacionam às forma de fazer matemática no cotidiano, muito embora a escola faça parte do cotidiano das crianças. Frente a isso, Walkerdine chama a atenção para a crença escolar de que exista uma equivalência lógica entre as atividades matemáticas escolares e não escolares, reforçada pela máxima que a "matemática está em toda a parte" (1995, p. 222).

Percebe-se que as práticas escolares preocupam-se em trabalhar uma matemática mais formal e científica, pois, como argumenta Lave,

a escola é uma forma institucional de primeira importância, em que se confirmam (e inculcam) postulados cognitivos acerca da prática científica e do «quotidiano». A escola é ela própria, frequentemente contraposta à vida cotidiana (1996, p. 111).

Em contrapartida, pontua a autora, alegadamente o senso comum encara a matemática do cotidiano como sendo uma ma-

3 Para maiores esclarecimentos, consultar Vilela (2007). temática inferior, por ela se caracterizar por ações simples, errôneas, rotineiras e concretas, contrastando com aquilo que se supõe ser o pensamento dos cientistas (Lave, 1996, p. 120).

Muito embora se perceba hoje uma preocupação para que não se naturalize a distinção que existe entre o saber científico $e$ os demais saberes, o dos outros, existe uma tendência a encarar a matemática escolar como superior, talvez por sua ênfase nos algoritmos, dando assim uma ideia de infalibilidade. Contudo, os estudos de Lave corroboram para que se questione tal postura.

Essa autora alerta-nos para alguns dados interessantes que surgem em suas pesquisas acerca da resolução de problemas matemáticos em situações escolares e extraescolares - no supermercado. De acordo com ela, é marcante a ausência de erros, quando os participantes estão resolvendo problemas relacionados ao seu cotidiano próximo a $99 \%$ de acertos - enquanto o mesmo já não acontece quando os mesmos estão resolvendo situações similares em testes estruturados - média de 60 a $70 \%$ de acertos.

A descontinuidade dos desempe-
nhos verificados entre os resultados
obtidos no ambiente de trabalho e
nos testes é de molde a sugerir que
mesmo a solução de problemas ma-
temáticos é uma atividade com es-
pecificidade situacional (LAVE,
1996, p. 115).

Tal constatação possibilita-nos traçar um parâmetro entre as práticas matemáticas desenvolvidas pelas crianças na escola $e$ fora dela. Existe todo uma conjuntura que influ- 
encia as formas de agir dos indivíduos, assim como, em se tratando de crianças de classes populares, pode-se inferir que existe um empenho maior das mesmas para que se saiam melhor em situações de seu cotidiano.

Em meio ao conflito entre a matemática escolar e a não escolar, fica evidente a existência de uma relação poder-saber na escola, onde apenas o saber das práticas científicas é aceito e tido como verdadeiro. Contudo, não podemos ignorar o fato de que podemos interagir de diferentes formas sobre uma dada situação e que não podemos falar de um saber universal, pois se esse fosse universal, não seria mais um saber! Nessa mesma lógica, Gottschalk elucida que "podemos olhar para o mesmo objeto e atribuir diferentes números para ele" (2007, p. 98), pois o pensamento matemático é diferente nas diferentes pessoas, enquanto as normas matemáticas são as mesmas para todos.

Buscando exemplificar tal percepção, a autora explica que "podemos ver as cartas de um baralho ora como um monte de cartas, ora como quatro naipes, ou ainda como cinquenta e duas cartas, e assim por diante" (Gottschalk, 2007, p. 98 - 99). E conclui que "os números não são propriedades das coisas, pois o modo como as coisas são numeradas depende de como olhamos elas: 'um objeto para o qual atribuo diferentes números com o mesmo direito não é o que realmente tem o número"".

Tal exemplo permite-nos pensar que existem diferentes lógicas ou pensamentos matemáticos possíveis para uma situação, e é o envolvimento de determinados sujeitos, e não outros, que darão o significado específico para a ocasião. Já Wittgenstein nos diria que existem diferentes jogos de linguagem de caráter matemático, ou ainda, que existem diferentes práticas matemáticas envolvidos nessa situação.

Lave também observou que, em situações de supermercado, os compradores utilizam-se de variadas estratégias para resolver o problema da "melhor compra" (2002, p. 86). Isso nos auxilia a pensar nas práticas nas quais os sujeitos se envolvem, pois em situações do cotidiano não podemos esperar por uma estratégia mais adequada como, por exemplo, a utilização de proporções ou o cálculo do preço unitário; contudo, uma mesma pessoa, em diferentes situações, fará uso de diferentes estratégias para a solução de situações naturais.

Vilela (2006) e Miguel e Vilela (2008), discorrendo sobre as ligações entre o social e a cognição, destacam a teoria de aprendizagem sócio-histórico-cultural cunhada por Lave, considerando que as aprendizagens matemáticas estão condicionadas pelas situações em que elas ocorrem. Essa noção defendida por Lave vem ao encontro do que se tem explorado neste estudo, uma vez que entende que a prática matemática não é única, mas assume enfoques diferentes e específicos de acordo com a conjuntura em que acontece.

Dizendo de outra forma, a atividade matemática - entendida como a prática de usar e mobilizar saberes matemáticos - pode ser entendida como uma prática social. As práticas sociais relacionam-se com as práticas discursivas, de tal forma que a primeira é a materialidade da segunda, ou seja, a prática social é constituída pela discursividade e suas formações discursivas. Considerando isso, quando me referir a práticas, subenten- 
da-se que estas são práticas discursivas, sociais e matemáticas.

Lave, através de suas pesquisas, chegou à conclusão de que não acontece uma transposição do conhecimento matemático de uma prática para outra. Um exemplo disso foi a utilização de operações aritméticas no ambiente escolar e fora dele, e a observação da forma com que as pessoas mobilizavam tais saberes.

[...] praticamente nenhum problema em uma loja ou na cozinha foi resolvido sob forma do algoritmo escolar. As regras de transformação (que eliminam aproximações algorítmicas para frações e decimais) não são transferidas, como também não o são as notações de posições fixas (já que lápis e papel não são utilizados), os cálculos, a trigonometria, álgebra etc. De fato, a questão deveria ser: "existe algo que é transferido?" (VILELA, 2006, p. 45 - 46).

Miguel e Vilela, buscando elucidar esse ponto de vista, colocam que alguns pesquisadores já sugerem que o ensino da Matemática já não pode mais ser explicado exclusivamente pelos estágios de desenvolvimento cognitivos, assim como por práticas que visam uma contextualização forçada dos conceitos matemáticos, "trazendo-se "problemas reais' para a escola” (2008, p. 106). Mas, que se precisa direcionar a busca por uma compreensão da "natureza dos sistemas usados" ou, em outras palavras, que precisamos nos concentrar nas práticas que envolvem as atividades matemáticas em meio às formas de vida dos sujeitos.

Com isso, temos que as situações de aprendizagem matemática estão intimamen- te ligadas ao âmbito em que as mesmas ocorrem, ou melhor, que a situação de aprendizagem matemática se "constitui no agir in situ" (Vilela, 2006, p. 46). E aproximando tais estudos da perspectiva da linguagem, podemos dizer que as práticas entendidas como discursivas, matemáticas e sociais - só terão significados para o indivíduo envolvido nela e no momento específico em que ela acontece. Ou seja, partindo-se do entendimento de cognição como prática regrada, passa-se a não dissociar a ação da mobilização do saber, uma vez que ambas estão em conexão.

Poderíamos dizer então que a criança não aprende Matemática - como entendem as teorias cognitivistas - mas adquire o conhecimento 4 em questão, seguindo regras de direção e sentido. Vilela, confirmando tal proposição, coloca a Matemática e os conteúdos curriculares no centro de uma prática em que relações de poder-saber ganham espaço.

[...] o signo "matemática escolar" é decodificado $e$ assim transparece sua pouca importância para a vida cotidiana, que prevalece na vida da maioria das pessoas. Transparece também seu papel reprodutor da ordem social, na medida em que assusta, inibe, segrega e discrimina os menos familiarizados com o mundo da escrita e da precisão da lógica matemática, pautada em princípios como o da identidade e da não contradição (2006, p. 47).

\footnotetext{
${ }^{4}$ Nesta perspectiva, o conhecimento está sendo entendido como o saber produzido pelo discurso científico.
} 
Neste sentido, a partir de uma perspectiva pós-estruturalista ${ }^{5}$, podemos entender a Matemática não mais como um produto formal e universal, mas sim como uma atividade para além do matemático ou do professor. Assim, a Educação Matemática, na contemporaneidade, passa a compreender a matemática como uma atividade que acontece nas práticas cotidianas. Acredito que poderíamos dizer ainda mais, que a Matemática tem sido vista como uma atividade imbricada às práticas e em conexão com as diferentes formas de vida.

De acordo com Miguel e Vilela (2008, p. 106), podemos entender a Matemática "como um conjunto variável de conhecimentos que pode ser representado de diferentes maneiras, por diferentes indivíduos, nas diferentes práticas em que esses conhecimentos são utilizados". E o ensino nesta perspectiva passa a ser visto como uma ação normalizadora, sendo seu sistema de regras adquirido pelos viventes através da observação e da instrução por parte de outros sujeitos. Por esta razão, intencionalmente, Wittgenstein não fazia uso da expressão aprender.

\footnotetext{
${ }^{5}$ Neste estudo entende-se por pós-estruturalismo um movimento de pensamento que se distancia do estruturalismo, que nos permite problematizar as produções discursivas. De acordo com Silva, o pósestruturalismo é um "Termo abrangente, cunhado para nomear uma série de análises e teorias que ampliam e, ao mesmo tempo, modificam certos pressupostos e procedimentos da análise estruturalista. Particularmente, a teorização pós-estruturalista mantém a ênfase estruturalista nos processos linguísticos e discursivos, mas também desloca a preocupação estruturalista com estruturas e processos fixos e rígidos de significação. Para a teorização pós-estruturalista, o processo de significação é incerto, indeterminado $e$ instável" (2000, p. 92).
}

\section{"Intencionalmente não digo aprende, mas} adquire"6

\begin{abstract}
É evidente que a gramática da palavra "saber" goza de estreito parentesco com a gramática das palavras "poder", "ser capaz". Mas também com a gramática da palavra "compreender". ('Dominar uma técnica') (WITTGENSTEIN, 2008, § 150).
\end{abstract}

Segundo o pressuposto de Wittgenstein, de que o significado das palavras dá-se através do seu uso na linguagem, como deveriam se dar os processos de ensino $e$ aprendizagem? Para Gottschalk, a forma tradicional de ensino não deve ser totalmente descartada, pois necessitamos apresentar novos conceitos aos educandos, mostrando suas diversas aplicações através de exemplos e, fundamentalmente, "mostrando como esses conceitos são utilizados no jogo de linguagem em questão" (2004, p. 6). Espera-se assim que, conhecendo como uma comunidade de prática opera com tal conceito, os educandos consigam operar corretamente com o mesmo.

Nesta perspectiva, contrariamente ao que defendem as perspectivas construtivistas, acredita-se que o ensino se procede ao mostrar ao educando os padrões e normas referentes aos saberes, apresentando o que Wittgenstein chama de regras do jogo e os procedimentos necessários para se jogar, acrescentando-se a isso um certo tipo de treino. A partir do momento em que o aluno domina as regras do jogo, bem como conse-

\footnotetext{
${ }^{6}$ Para este subtítulo, teve-se por inspiração uma expressão célebre de Wittgenstein acerca da aprendizagem.
} 
gue jogar, é que faz sentido apresentar problemas que envolvam situações empíricas $e$ desafios. Como destaca Gottschalk,

[...] é fundamental através do método da exemplificação que o aluno vai se capacitando gradualmente a aplicar os conceitos e procedimentos aprendidos em situações e contextos cada vez mais variados e mesmo inusitados. O que consideramos importante ressaltar é que, desse ponto de vista, embora o treino seja condição essencial para transitar num novo jogo de linguagem, o processo de aprendizado é no sentido de ampliar horizontalmente as possibilidades de fazer, compreender e explicar, transcendendo o que se é explicado pelo professor (2004, p. 8).

A mesma autora, ao concluir uma de suas reflexões, destaca o papel do professor e do aluno frente a essa nova perspectiva de ensino e aprendizagem. Para ela, cabe ao professor estabelecer as conexões entre os conceitos matemáticos e os significados dentro dos diferentes jogos de linguagem. De acordo com suas palavras,

[...] é papel do professor introduzir as regras do jogo, e não esperar que o aluno a deduza, ou que se limite ao seu uso empírico. Uma vez apresentadas, agora sim, cabe ao aluno explorar as possibilidades de sua aplicação em situações teóricas ou práticas, conjecturando $e$ até, quem sabe, inventando (GOTTSCHALK, 2004, p. 9).

Frente a tais colocações, não podemos nos limitar a falar em matemática, mas sim, em matemáticas. A existência de dife- rentes formas de fazer matemática, entre outras ideias fundamentais, leva-nos a entendê-la, neste estudo, para além de uma prática social - como defende Lave - mas como uma atividade. E um episódio que reforça tal ideia foi quando se perguntou a Wittgenstein "O que é a matemática?", ao que ele filosoficamente respondeu com outra pergunta: "Por que eu não deveria dizer que o que chamamos de matemática é uma família de atividades com uma família de propósitos?" (Miguel, 2008, p. 394).

Miguel (2008, p. 395) ainda complementa os argumentos de Wittgenstein, colocando que

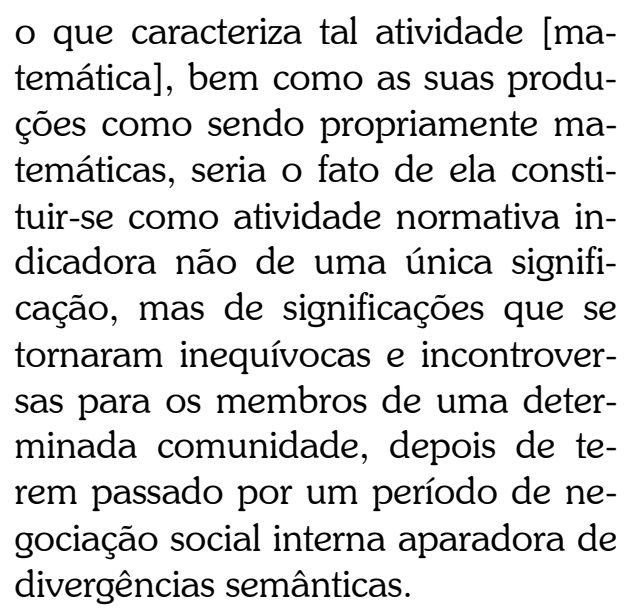

De acordo com Lektorsky, a atividade humana caracteriza-se por ser coletiva e resultante da apropriação de formas culturais, dentro de um contexto histórico. A atividade coletiva não deve ser considerada uma ampliação da atividade individual, pois, como coloca o autor,

a atividade coletiva não é uma simples extensão de uma atividade individual, uma vez que a atividade coletiva pressupõe relações interindividuais, e não simples atividades $e$ 
ações, mas interatividades e interações. Interatividades $e$ interações podem ser entendidas como comunicação e este é um ponto muito importante (2009, p. 8).

Sendo a atividade coletiva, caracterizada pela presença de interações e de comunicação, podemos considerar a aprendizagem também como uma atividade. Outro ponto que nos leva a entender a aprendizagem como uma atividade é a existência de metas, pois de acordo com Lektorsky, a atividade coletiva "pressupõe uma meta que é comum a todos os participantes e não pode ser alcançada separadamente por eles, mas somente na interação". Contudo, as formas de se alcançar essa meta podem ser diferentes; logo, as atividades coletivas - $e$ a aprendizagem - também podem acontecer de formas diferentes.

Aproximando tais argumentações da perspectiva wittgensteiniana, a aprendizagem, aqui entendida como uma atividade coletiva em um contexto histórico determinado, pode ser entendida como divulgadora das regras dos jogos de linguagem. E é através dela - da atividade - que os sujeitos podem fazer uso das diferentes regras, bem como aplicá-las em diferentes contextos. E, quando aplicamos as regras dos jogos de linguagem em atividades naturais, acabamos por fazer isto sem consultar um conjunto de formulações de regras (Glock, 1998, p. 67).

Assim, pensando a aprendizagem com uma atividade, cabe colocar que esta não se restringe apenas ao âmbito coletivo. Em meio às atividades, que são práticas coletivas, temos que "os processos de interiorização devem ser compreendidos não como resultado da transformação da atividade in- dividual, mas como uma forma de apropriação individual das formas coletivas de atividade" (Lektorsky, 2009, p. 9). Em suma, as atividades são ações que constituem significados imersas em seus usos, ou ainda, numa perspectiva wittgensteiniana, em seus jogos de linguagem. Frente a esse panorama, Lektorsky sugere que existem jogos de práticas que, assim como os jogos de linguagem, funcionam de acordo com regras específicas.

Voltando à questão da impossibilidade dos indivíduos de fazerem a transposição dos conceitos matemáticos de uma prática para outra, podemos dizer que isso acontece pela inexistência de pontes entre essas práticas? Seria essa ponte a semelhança de família entre os jogos de linguagem em questão? De acordo com Veiga-Neto, atravessar tal ponte não acarretaria que os significados chegariam ao outro lado intactos. Bem pelo contrário, "a ponte não funciona como um vaso comunicante, pois as partes ligadas não se identificam, isto é, nem se igualam, nem se homogeneízam" (2004, p. 144).

Considerando que, ao cruzar a ponte, os significados transformam-se, visto que do outro lado existem outras formas de vida $e$ outras práticas, bem como suas regras, não podemos entender tais pontes como sendo as semelhanças de família presentes na teoria wittgensteiniana. Da mesma forma, não podemos esperar que aconteça uma transferência de um significado matemático de uma forma de vida para a outra.

Da mesma forma como nos questionamos como uma palavra é aprendida, devemos nos questionar como ensinar a uma criança o uso de uma palavra ou expressão. Para Spaniol, ensinamos como se utiliza uma palavra no próprio contexto de seu uso, 
e fizemos isso, normalmente, de forma inconsciente. De acordo com o ele, "a pergunta como se aprende ou se ensina uma palavra pode despertar nossa atenção para certas circunstâncias decisivas no emprego da palavra em questão, mas que não temos nem podemos ter consciência no momento da fala" (1989, p. 78).

Usando-se dessa mesma lógica, se quisermos saber qual o significado de uma palavra ou expressão para nós, é só buscarmos na forma que nos foi ensinado a utilizála. Segundo Spaniol,

[...] descobrimos, não que o professor nos levou a adivinhar o que se passou em sua mente ao nos apresentar a fórmula, mas que fomos educados "para executar essas atividades, para usar essas palavras ao executá-las, e para reagir assim às palavras dos outros" (1989, p. 79).

Tais colocações fazem-nos realmente repensar a forma como os educadores acreditam que acontece a aprendizagem de seus alunos. Temos presentes no discurso da Educação Matemática uma forte influência das teorias construtivistas de ensino, sejam elas de ênfase no meio físico, social ou cultural. Contudo, é claro que tais concepções que defendem inclusive que a criança aprende através de estágios lineares de desenvolvimento - não dão conta de explicar e justificar por que muitas crianças não conseguem ter sucesso na escola, bem como se engessam em situações de sub-rendimento.

"Esperar que a matemática possa ser construída espontaneamente pelas crianças sob determinadas condições de natureza cognitiva, empírica ou social", assim como, "esperar que a partir de 'problemas verdadeiramente reais' surjam os diversos conhecimentos de uma forma integrada" são dois equívocos comuns na Educação Matemática para Gottschalk (2004, p. 2). A partir da concepção de Wittgenstein de que "as proposições matemáticas podem ser vistas como regras a serem seguidas", Gottschalk (2004, p. 3) argumenta que muitos dos saberes matemáticos evidentemente não decorrem de ações espontâneas das crianças sobre a "realidade", nem são resultados de interações sociais, mas, sim, de uma função normativa.

Wittgenstein coloca-nos que a expressão " $2+2=4$ " é verdadeira, porque assim se instituiu tal regra; contudo a mesma não é verdadeira para toda e qualquer proposição empírica - para uma compreensão inicial de tal ideia, basta que troquemos a base do sistema de numeração. Podemos também pensar " $2+2=4$ " na forma de proposição descritiva como convidei dois casais de amigos para um jantar, ou ainda, como convidei quatro amigos para um jantar, muito embora, ao contar as pessoas que se fizeram presentes ao meu jantar, eu encontre apenas três, dois ou até mesmo nenhum amigo.

Assim, a contagem não invalida a regra " $2+2=4$ " ou, como coloca Gottschalk, "A experiência não refuta a regra" (2004, p. 3). Neste sentido, o papel que as proposições matemáticas desempenham em nossa linguagem é essencialmente diferente do das proposições descritivas e hipotéticas de nossa realidade.

Para Wittgenstein, a geometria, a aritmética, a probabilidade etc., são jogos de linguagem, ou seja, com características distintas dos jogos das ciências empíricas. De acordo com tais colocações, não podemos 
manter a suposição de que a Matemática se aprende através de orientações construtivistas, como nos parece ainda ser defendido pelo discurso escolar. Da mesma forma, podemos equivocadamente pensar que um educando abstraia a partir do concreto, ou inda, que ele transponha os conhecimentos escolares para sua prática cotidiana. Segundo Walkerdine, o que temos é "um movimento de uma prática discursiva para outra" (2004, p. 118).

Levar os educandos a construir de forma autônoma um novo conceito é algo improvável para Wittgenstein, pois para ele "Não se pode adivinhar como uma palavra funciona. É preciso que se veja a sua aplicação e assim se aprenda" (2008, §340). Neste entendimento, as proposições matemáticas só adquirem significados quando operamos com elas, ou seja, cada proposição matemática terá seu significado dado no âmago das formas de vida e de acordo com os jogos de linguagem presentes nas mesmas.

Gottschalk nos chama a atenção para as confusões que podem acontecer em função da Matemática institucionalizada aparentemente ter aplicações no mundo empírico:

Ora, esta característica do jogo de linguagem da matemática dá origem à seguinte confusão: a crença de que suas proposições decorrem da realidade, passíveis de serem descobertas pelos alunos através da formulação de hipóteses sobre ela e de experimentações empíricas, ou mesmo através de intuições. Ignora-se, assim, a função de suas proposições, pois passam a ser tratadas como descritivas, ao invés de normativas. Esquece-se que as relações entre as proposições matemáticas e os diversos contextos em que são utilizadas são convencionais. Não há um vínculo "natural", "intrínseco" entre a matemática e a realidade. São relações arbitrárias que variam de contexto a contexto (2004, p. 6).

Tal colocação explica, em parte, o fato de que embora se espere que o aluno realize a transferência de saberes - nesse caso, do contexto da sala de aula para o do seu cotidiano - e o fato de tal desdobramento não ocorrer. A autora ainda complementa,

Não há uma transposição imediata de contextos do cotidiano para o escolar. Os raciocínios empregados no cotidiano estão ligados a contextos específicos e são de natureza diferente dos raciocínios empregados na matemática escolar e, por conseguinte, os significados de proposições ou termos matemáticos podem diferir radicalmente em função dos contextos linguísticos ou empíricos em que estão sendo usados (GOTTSCHALK, 2004, p. 6).

Um exemplo bastante simples utilizado pela autora para ilustrar tais colocações é a situação de ensino do conceito de triângulo. Na linguagem cotidiana, tal conceito pode ser compreendido como um instrumento musical ou como um sinal de trânsito ou, ainda, como um objeto obrigatório dentre os equipamentos de um veículo. Já, no contexto escolar, existe todo um sistema geométrico que lhe dá significado.

Caso semelhante acontece quando nos propomos a ensinar aos alunos a propriedade dos ângulos internos dos triângulos. Embora exista uma orientação para que os educandos sejam conduzidos a construir tal 
propriedade, verificando através da construção e da medição dos ângulos internos de um triângulo, eles, via de regra, não encontram a medida de $180^{\circ}$. São exemplos como esses que nos levam a acreditar que os saberes matemáticos de fato não advêm de proposições empíricas, mas, sim, de proposições normativas.

\section{Considerações finais}

Aprender, numa perspectiva wittgensteiniana, passa a ser o domínio dos jogos de linguagens - bem como suas regras - envolvidos em uma prática social específica. Vilela corrobora com tal concepção, quando coloca que "Aprender é compartilhar significados em diversos usos, participar de diferentes jogos de linguagem, é compartilhar os sentidos, códigos e regras socialmente acordados" (2006, p. 48). A linguagem não apenas comunica, mas passa a constituir os indivíduos.

Ainda de acordo com Miguel e Vilela, para Lave, a aprendizagem "não é encarada como um processo de adquirir saber, de memorizar procedimentos ou fatos, mas é considerada como uma forma evolutiva de pertença" (2008, p. 114) a uma comunidade que, na perspectiva wittgensteiniana, podemos entender como pertencimento a uma forma de vida.
Então, podemos colocar que as práticas matemáticas escolares e não escolares fazem parte de diferentes jogos de linguagem, o que explicaria o fato de não haver uma transposição dos conhecimentos de um contexto para o outro. E frente a tal ideia, conforme sugerem Miguel e Vilela (2008, p. 112), podemos aceitar, no máximo, que existam semelhanças de família entre essas práticas matemáticas.

Assim, é possível compreender como a matemática se relaciona com as práticas sociais e culturais. Logo, se na contemporaneidade colocamo-nos como professores de Matemática para problematizar as questóes escolares a partir de uma lógica em que existe uma disciplina Matemática, poderemos perceber que tais questões são discursivas. Ao avançarmos para a filosofia de Wittgenstein e de outros autores brasileiros como Miguel e Vilela - que discutem as matemáticas como práticas - poderemos perceber ainda, que este caráter disciplinar é meramente ilusório ou é apenas uma estratégia institucional do campo escolar. E, tais práticas extrapolam o âmbito disciplinar, é possível pensar "O fim do encanto da Matemática".

\section{Referências}

GLOCK, H. Dicionário Wittgenstein. Tradução de Helena Martins. Rio de Janeiro: Editora Jorge Zahar, 1998.

GOTTSCHALK, C. Três Concepções de Significado na Matemática: Bloor, Granger e Wittgenstein. In: MORENO, Arley R. (org.). Wittgenstein: aspectos pragmáticos. Campinas: Coleção CLE, 49, 2007, p. 95-133. 
GOTTSCHALK, C. Reflexões sobre o Contexto e Significado na Educação Matemática. In: Anais do VII Encontro Paulista de Educação Matemática. São Paulo, SP, 2004, p.1-9.

LAVE, J. Do lado de fora do supermercado. In: FERREIRA, M. L. Ideias matemáticas de povos culturalmente distintos. São Paulo: Global, 2002, p. 65-98.

LAVE, J. A selvajaria da mente domesticada. Revista Crítica de Ciências Sociais, 46, 1996, p.109-134.

LEKTORSKY, V. A. Mudanças históricas da noção de atividade: pressupostos filosóficos. Tradução de Samuel Bello e Antônio Miguel. Porto Alegre. (Texto digitado). 2009.

MIGUEL, A. Áreas e subáreas do conhecimento, vínculos epistemológicos: o GT de Educação Matemática da ANPEd. Revista Brasileira de Educação, 13, 38, 2008, p.387-396.

MIGUEL, A.; VILELA, D. Práticas escolares de mobilização de cultura matemática. Cadernos Cedes, Campinas, 28, 74, 2008, p.97-120.

SILVA, T. T. da. Teoria cultural e educação: um vocabulário crítico. Belo Horizonte: Autêntica, 2000.

SPANIOL, W. Filosofia e método no segundo Wittgenstein: uma luta contra o enfeitiçamento do nosso entendimento. São Paulo: Loyola, 1989.

VEIGA-NETO, A. Nietzsche e Wittgenstein: alavancas para pensar a diferença e a pedagogia. In: GALLO, Sílvio; SOUZA, Regina M. (Org.). Educação do preconceito: ensaios sobre poder e resistência. Campinas: Alínea, 2004. p. 131-146.

VILELA, D. S. Matemáticas nos usos e jogos de linguagem: ampliando concepções na Educação Matemática. 2007. (Tese de Doutorado). Universidade Estadual de Campinas, Campinas.

VILELA, D. S. Notas sobre a matemática escolar no referencial sócio-histórico-cultural. Revista Horizontes, 24, 1, 2006, p.43-50.

WALKERDINE, V. O Raciocínio em tempos pós-modernos. Educação \& Realidade, Porto Alegre, 20, 2, 1995, p.207-226.

WITTGENSTEIN, L. Investigações Filosóficas. Tradução de Marcos G. Montagnoli. Petrópolis: Vozes, 2008.

Recebido em: $13 / 02 / 2020$

Aprovado em: 16/10/2020 